\title{
Low Cerebrospinal Fluid Amyloid-Beta Concentration Is Associated with Poorer Delayed Memory Recall in Women
}

\author{
Fanni Haapalinna $^{a}$ Teemu Paajanen $^{d}$ Janne Penttinen $^{a}$ Hannu Kokki $^{c}$ \\ Merja Kokkic Anne M. Koivisto $^{b}$ Päivi Hartikainen ${ }^{b}$ Eino Solje ${ }^{a}$ \\ Tuomo Hänninen $^{b} \quad$ Anne Marja Remes ${ }^{a}$ b Sanna-Kaisa Herukka ${ }^{a}$ b \\ a Department of Neurology, Institute of Clinical Medicine, University of Eastern Finland, \\ and Departments of ${ }^{b}$ Neurology and ${ }^{\mathrm{c}}$ Anesthesia and Operative Service, Kuopio University \\ Hospital, Kuopio, and ${ }^{\mathrm{d}}$ Finnish Institute of Occupational Health, Mental Health and \\ Cognition Team, Helsinki, Finland
}

Key Words

Alzheimer's disease - Mild cognitive impairment - CERAD - Cerebrospinal fluid · Cognition . Delayed recall $\cdot$ Screening dementia

\section{Abstract}

Background: Data on the association of memory performance with cerebrospinal fluid (CSF) biomarkers of Alzheimer's disease (AD) are inconsistent. The Consortium to Establish a Registry for Alzheimer's Disease neuropsychological battery (CERAD-NB) is a commonly used validated cognitive tool; however, only few studies have examined its relationship with CSF biomarkers for AD. We studied the correlation of pathological changes in CSF biomarkers with various CERAD-NB subtests and total scores. Methods: Out of 79 subjects (36 men, mean age 70.5 years), 63 had undergone an assessment of cognitive status with CERAD-NB and a CSF biomarker analysis due to a suspected memory disorder, and 16 were controls with no memory complaint. Results: In women we found a significant correlation between CSF amyloidbeta $\left(A \beta_{1-42}\right)$ and several subtests measuring delayed recall. Word List Recall correlated with all markers: $A \beta_{1-42}(r=0.323, p=0.035)$, tau $(r=-0.304, p=0.050)$ and hyperphosphorylated tau ( $r=-0.331, p=0.046)$. No such correlations were found in men. Conclusions: CSF biomarkers correlate with delayed memory scores in CERAD-NB in women, and women may have more actual $A D$ pathology at the time of the investigations than men. 


\section{Introduction}

Memory diseases are common [1], and Alzheimer's disease (AD) is the leading cause of dementia, accounting for $50-56 \%$ of all cases [2]. The final diagnosis of AD is achieved by a brain biopsy [3]. Currently, clinical diagnosis is based on a comprehensive clinical evaluation, which includes detecting typical symptoms such as impairment in cognition (typically episodic memory), poor judgment, brain imaging and pathological laboratory findings for AD [4]. An earlier and more specific diagnosis of AD is warranted for the further development of disease-modifying drugs that are considered most effective at the preclinical or prodromal stages of the disease $[3,5]$.

The pathologic process of AD has been proposed to begin decades prior to the appearance of the clinical symptoms [6-8]. It has been found that the concentration of cerebrospinal fluid (CSF) beta-amyloid consisting of 42 amino acids $\left(A \beta_{1-42}\right)$ has decreased, and the concentrations of tau and phosphorylated tau ( $p$-tau) have increased in patients diagnosed with AD [9], thus correlating with the amyloid and neurofibrillary tangle load of the brain [10]. All biomarkers mentioned have been found to deviate from normal already early in the course of the disease [11]; together, they have a high diagnostic accuracy: a 95\% sensitivity and an 83\% specificity [3]. Hence, they have been introduced for the clinical diagnosis of AD [8].

The Consortium to Establish a Registry for Alzheimer's Disease neuropsychological battery (CERAD-NB) is a widely used cognitive battery to measure typical cognitive deficits in AD [12]. The battery consists of five subtests: Verbal Fluency; Boston Naming Test; MiniMental State Examination; Word List Learning, Recall and Recognition and Constructional Praxis and its Recall $[12,13]$. Usually, cut-off values for these subtests are used for the interpretation. However, studies by Paajanen et al. [12] and Seo et al. [13], among others, have proved that CERAD Total Scores achieved by summing scores from the subtests are also useful in the assessment. Since the impairment of episodic memory is typically the first clinical outcome in $\mathrm{AD}$, a compound score measuring delayed memory, the Memory Total Score, was created by Paajanen et al. [12]. The Memory Total Score and Word List Delayed Recall have been found to differentiate especially well between controls and Mild Cognitive Impairment (MCI) or prodromal AD [12].

Only a few studies have evaluated the relationship between memory and CSF biomarkers. In most of these studies, merely Word List Immediate Recall (learning) and delayed recall trials from the CERAD-NB have been used [14-16]. It has been suggested that there is no association between CSF markers and cognitive tests in AD patients [15-17], whereas patients with subjective memory complaint or $\mathrm{MCI}$ show a significant association between markers and memory tests measuring delayed recall. Wagner et al. [15] and Rami et al. [16] reported that tau protein is more closely associated with cognition than $A \beta_{1-42}$, which appears to support the theory that $\mathrm{CSF} A \beta_{1-42}$ declines already at the preclinical stage of $\mathrm{AD}$, before the increase in CSF tau concentration $[8,18]$. Accordingly, by the time the clinical symptoms of $A D$ appear, $A \beta_{1-42}$ would have reached a plateau and thus would not correlate with memory performance anymore $[15,16,19]$. However, some studies have found no correlation between CSF tau and any cognitive tests, whereas $A \beta_{1-42}$ has been suggested to correlate with delayed memory tasks also in MCI [14].

The aim of this study was to investigate the correlation of pathological changes in the CSF biomarkers with various CERAD-NB subtests, the CERAD Total Score and the Memory Total Score. 
Table 1. Characteristics of the study subjects

\begin{tabular}{|c|c|c|c|c|c|}
\hline & $\begin{array}{l}\text { All subjects } \\
(\mathrm{n}=79)\end{array}$ & $\begin{array}{l}A D \\
(n=25)\end{array}$ & $\begin{array}{l}\text { MCI } \\
(n=19)\end{array}$ & $\begin{array}{l}\text { Control } \\
(n=16)\end{array}$ & $\mathrm{p}$ value \\
\hline Female/male & $43 / 36$ & $18 / 7$ & $7 / 12$ & $9 / 7$ & \\
\hline Age, years & $70.5(7.5)$ & $70.9(7.3)$ & $76.0(7.3)$ & $70.1(6.7)$ & n.s. \\
\hline $\mathrm{CSF} A \beta_{1-42}, \mathrm{pg} / \mathrm{ml}$ & $628(254)$ & $478(142)$ & $658(309)$ & 779 (187) & n.s. \\
\hline CSF tau, pg/ml & $416(293)$ & $601(338)$ & $457(334)$ & $245(96)$ & n.s. \\
\hline CSF p-tau, pg/ml & $74(34)$ & $97(37)$ & $76(35)$ & $56(20)$ & n.s. \\
\hline MMSE $(0-30)$ & $23.5(4.4)$ & $21(3.5)$ & $24.4(3.2)$ & $26.2(5.1)$ & $0.039 *$ \\
\hline Verbal Fluency $(0-24)$ & $14.0(5.5)$ & $13.3(5.1)$ & $14.7(4.5)$ & $18.1(3.8)$ & $0.020^{*}$ \\
\hline Word List Delayed Recall, n (\%) & $61(32)$ & $49(30)$ & 60 (29) & $85(25)$ & $0.002^{* *}$ \\
\hline Constructional Praxis Recall, n (\%) & $64(33)$ & $45(28)$ & $66(30)$ & $85(29)$ & $0.029 *$ \\
\hline CERAD Total Score ${ }^{\mathrm{a}}(0-111)$ & $66(16)$ & $59(12)$ & $67(16)$ & $78(15)$ & $0.045^{*}$ \\
\hline Memory Total Score ${ }^{\mathrm{b}}(0-41)$ & $26.5(6.3)$ & $22.6(4.6)$ & $26.8(6.0)$ & $31.7(6.4)$ & $0.014^{*}$ \\
\hline Learning Efficiencyc $(1-10)$ & $1.7(0.7)$ & $1.5(0.5)$ & $2.0(1.0)$ & $1.7(0.5)$ & n.s. \\
\hline Executive Function Score $^{\mathrm{d}}(1-30)$ & $20.0(6.9)$ & $19.2(6.8)$ & $21.0(5.5)$ & $24.7(5.3)$ & n.s. \\
\hline
\end{tabular}

Data are numbers of cases or means (SD), unless otherwise indicated. p values are given for the differences between $\mathrm{AD}, \mathrm{MCI}$ and control groups. n.s. = Not significant; MMSE = Mini-Mental State Examination. ${ }^{a}$ According to Seo et al. [13]. ${ }^{\mathrm{b}}$ According to Paajanen et al. [12]. ${ }^{\mathrm{c}}$ Word List Memory (3rd trial - 1st trial). $\mathrm{d}$ CERAD Word List Learning Efficiency Score (0-10) + Verbal Fluency (0-24) + Clock-Drawing test score. $* \mathrm{p} \leq 0.05 .{ }^{* *} \mathrm{p} \leq 0.005$.

\section{Materials and Methods}

\section{Subjects}

A total of 79 subjects participated in the present clinical follow-up study at the Neurology Outpatient Clinic of the University of Eastern Finland (UEF) and Kuopio University Hospital (KUH). All subjects who both agreed to participate in this study and underwent an assessment of cognitive status with CERAD-NB and CSF biomarker analysis between June 2008 and May 2013 were included in the study. One subject was excluded owing to missing CERAD-NB values due to poor cooperation. The final sample consisted of 79 subjects ( 36 men) with a mean age of 70.5 years (range 51-84) (table 1). Sixty-three subjects had undergone investigations due to a suspected memory disorder, and 16 were controls with no memory complaint. Out of the subjects with suspected memory disorder, a total of 25 subjects were diagnosed with AD, 19 with MCI, 12 with frontotemporal dementia and 7 with another memory problem, such as a memory deficit due to depression. Sixteen subjects with no memory complaint were recruited from the Department of Anesthesia and Operative Service. They were patients who were operated under spinal anesthesia and from whom CSF samples were obtained through a catheter in the beginning of the operation. The CERAD-NB was performed on a separate visit. Standard criteria were used to diagnose AD [20], MCI [21] and frontotemporal dementia [22].

\section{Measurements}

The CSF A $\beta_{1-42}$, total-tau and p-tau concentrations were measured using a commercial ELISA (Innogenetics, Ghent, Belgium) according to the manufacturer's protocol. Samples were measured in duplicates, and the results were analyzed blinded to diagnosis.

CERAD

The cognition of all subjects was assessed with CERAD-NB by a nurse or a bachelor of medicine trained for CERAD testing or a neuropsychologist specialized in neurodegenerative 
disorders. Two compound scores, the Memory Total Score and the CERAD Total Score, were calculated. The Memory Total Score (score range 0-41) by Paajanen et al. [12] is based on the summation of all CERAD delayed memory scores (Word List Recall, Word List Recognition and Constructional Praxis Recall); CERAD Total Score suggested by Seo et al. [13] (score range $0-111$ ) is an extended version of the original CERAD Total Score by Chandler et al. [23] and additionally includes the Constructional Praxis Recall score. Moreover, we created a compound score to measure the efficiency of the Word List Learning: Word List Learning Efficiency, the relation of the third Word List Recall to the first recall (1-10). In addition, we constructed a compound score for Executive Function in CERAD-NB. This score combines the Word List Rehearsal Benefit, Verbal Fluency and Clock-Drawing Test. Although the Clock-Drawing Test is not included to the original CERAD-NB, we had this option as it is an additional test in the Finnish CERAD battery [24].

\section{Statistical Analyses}

The data was entered, and the statistical analyses were conducted using IBM SPSS Statistics version 21.0 for Windows (IBM, Chicago, Ill., USA). The Kolmogorov-Smirnov test was used to test the normality of the variables, and the results for these variables are presented as mean (SD). For other variables, the results are presented as the number of subjects when appropriate. Differences between the two groups were analyzed using the Mann-Whitney U test, whereas differences between several groups were measured using the Kruskal-Wallis test. Pearson correlation was used to analyze correlations between continuous variables, such as the CERAD-NB subtest values and CSF biomarker concentrations. A two-sided $p$ value of 0.05 was considered the limit of statistical significance.

\section{Statement of Ethics}

The study was approved by the Research Ethics Committee of the Northern Savo Hospital District, Kuopio, Finland, and was conducted in accordance with the principles of the Declaration of Helsinki. All subjects agreed to participate in the study, and blood and CSF samples were collected after obtaining a written informed consent from the studied subjects, their legal representatives, or both.

\section{Results}

\section{Demographic Differences within the Cohort}

Table 1 presents the demographic information, CSF biomarker values and key CERAD test results of the studied subjects. In the total study sample, there was a statistically significant difference in the CSF $p$-tau $(p=0.006)$ concentration between sexes but not in CSF $\mathrm{A} \beta_{1-42}(\mathrm{p}=0.370)$ and tau $(\mathrm{p}=0.120)$. In AD women, the CSF tau concentration was higher than in men in the same diagnostic group ( $p=0.041)$. Moreover, in the MCI group the CSF concentration of $A \beta_{1-42}$ was significantly lower in women than in men $(p=0.036)$. However, the mean age within diagnostic groups did not differ significantly between men and women (AD: $\mathrm{p}=0.576$; MCI: $\mathrm{p}=0.494$; controls: $\mathrm{p}=0.174$ ).

When evaluating differences between the diagnostic groups including both sexes, the concentration of CSF $A \beta_{1-42}$ was found to be significantly lower in the AD group than in the MCI group ( $p=0.048)$. Moreover, the CSF $A \beta_{1-42}$ concentration was significantly decreased $(\mathrm{p} \leq 0.001)$, and tau and $\mathrm{p}$-tau concentrations were increased $(\mathrm{p} \leq 0.0001)$ in the AD group compared to the control group. 
Fig. 1. The association of Word List Delayed Recall (0-10) with CSF $A \beta_{1-42}$ in women from all diagnostic groups.
Fig. 2. The association of Word List Delayed Recall (0-10) with $\mathrm{CSF} A \beta_{1-42}$ in men from all diagnostic groups.
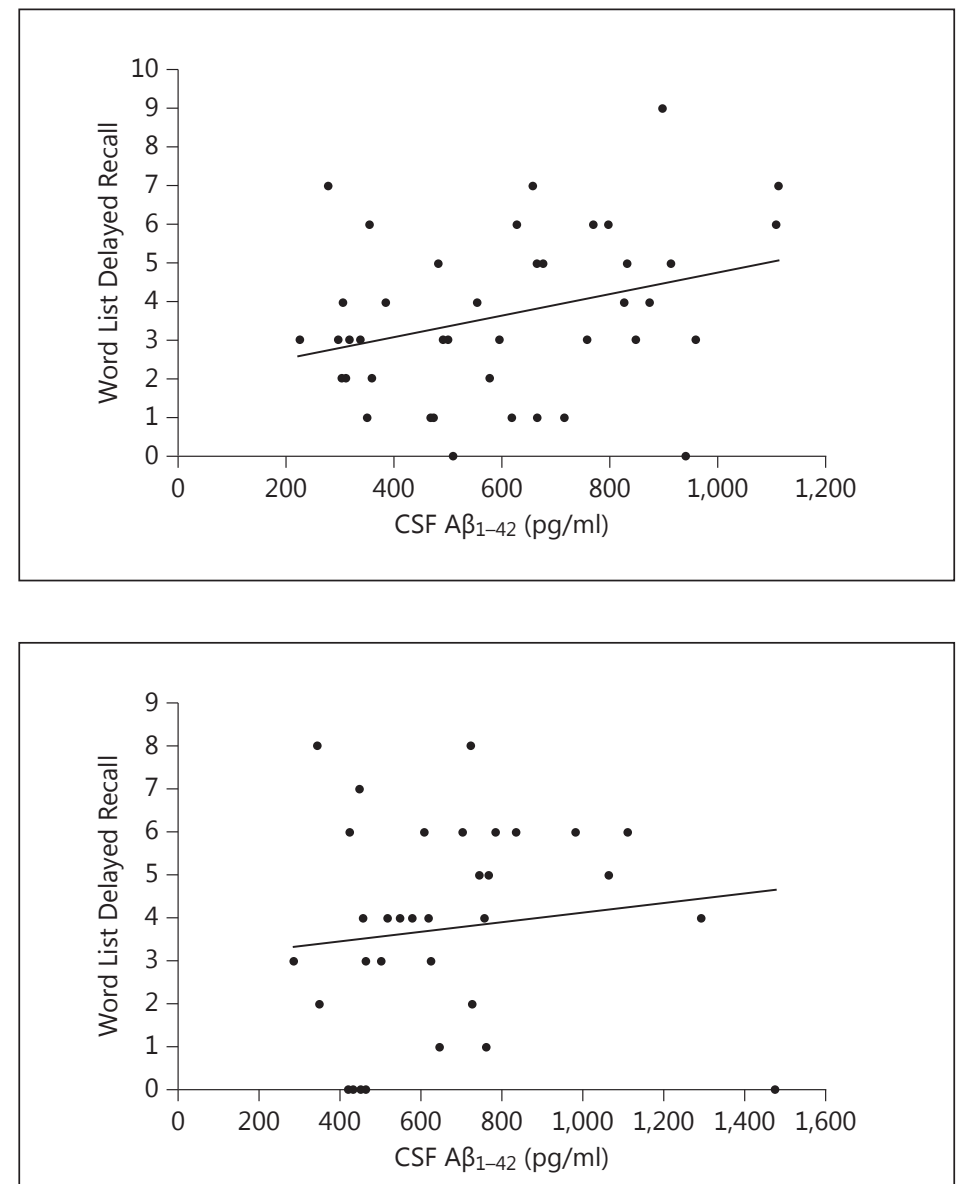

CSF Biomarker Correlations with Memory Performance in the Total Cohort

When the whole study group was examined, we found a significant association between a low CSF $A \beta_{1-42}$ concentration and declined memory performance in women, especially in several subtests measuring delayed recall. Word List Delayed Recall correlated with all markers: $A \beta_{1-42}(r=0.323, p=0.035)$ (fig. 1$)$, tau $(r=-0.304, p=0.050)$ and $p$-tau $(r=-0.331$, $\mathrm{p}=0.046)$. The decrease in $\mathrm{CSF} A \beta_{1-42}$ was associated with a lower Constructional Praxis Recall percentage value $(r=0.345, p=0.049)$, CERAD Total Score $(r=0.458, p=0.008)$ and Memory Total Score $(r=0.403, p=0.020)$. In men, on the other hand, none of the CSF biomarkers correlated with memory tests or scores (table 2, fig. 2).

\section{CSF Biomarker Correlations with Memory Performance in Different Diagnostic Groups}

In the $\mathrm{MCI}$ group including both sexes, $\mathrm{A} \beta_{1-42}$ correlated significantly with Word List Delayed Recall $(r=0.540, p=0.017)$ and its percentage value $(r=0.639, p=0.003)$. In addition, there was a significant negative correlation between $A \beta_{1-42}$ and Word List Learning Efficiency $(\mathrm{r}=-0.483, \mathrm{p}=0.036)$. Similar correlations could not be found in subjects diagnosed with AD. Moreover, in MCI subjects, Word List Recognition and Memory Total Score were significantly associated with gender: women had considerably lower raw and percentage values in terms of recognition than men $(15.4,76$ and $18.5,93 \%$, respectively; $p=0.001)$ and statistically a significantly lower Memory Total Score (21.0 and 29.1, respectively; p = 0.042). However, there was no significant correlation between these variables and CSF biomarkers (table 2). 
Table 2. The relationship between CSF biomarkers and the CERAD-NB subtests and compound scores in the different diagnostic groups

\begin{tabular}{|c|c|c|c|c|c|}
\hline Group & Variable & Women & Men & Both sexes & Correlation with CSF biomarkers \\
\hline All & Verbal Fluency $(0-24)$ & $14.6(5.0)$ & $13.3(5.9)$ & $14.0(5.5)$ & n.s. \\
\hline \multirow[t]{5}{*}{ patients } & Word List Delayed Recall & $3.6(2.1)$ & $3.7(2.4)$ & $3.7(2.2)$ & $\begin{array}{l}\text { women: } p=0.035\left(\mathrm{~A} \beta_{1-42}\right), \mathrm{p}=0.050^{*} \\
(\mathrm{tau}), \mathrm{p}=0.046(\mathrm{p}-\mathrm{tau}) \\
\text { all: } \mathrm{p}=0.048\left(\mathrm{~A} \beta_{1-42}\right)\end{array}$ \\
\hline & Word List Delayed Recall, n (\%) & $59.3(28.1)$ & $62.1(36.6)$ & $60.6(32.0)$ & n.s. \\
\hline & Constructional Praxis Recall, n (\%) & $60.9(32.9)$ & $67.0(33.6)$ & $63.6(33.1)$ & $\begin{array}{l}\text { women: } p=0.049\left(\mathrm{~A} \beta_{1-42}\right) \\
\text { all: } \mathrm{p}=0.026\left(\mathrm{~A} \beta_{1-42}\right), \mathrm{p}=0.047^{*}(\mathrm{tau})\end{array}$ \\
\hline & CERAD Total Score ${ }^{\mathrm{a}}(0-111)$ & $65.1(14.2)$ & $66.4(18.9)$ & $65.7(16.3)$ & women: $p=0.008\left(A \beta_{1-42}\right)$ \\
\hline & Word List Learning Efficiency ${ }^{\mathrm{b}}(1-10)$ & $1.7(0.8)$ & $1.7(0.7)$ & $1.7(0.7)$ & n.s. \\
\hline \multirow[t]{6}{*}{$\mathrm{AD}$} & Verbal Fluency $(0-24)$ & $14.8(4.5)$ & $9.43(4.6)$ & $13.3(5.1)$ & n.s. \\
\hline & Word List Delayed Recall & $2.7(1.7)$ & $2.6(2.6)$ & $2.7(1.9)$ & n.s. \\
\hline & Word List Delayed Recall, n (\%) & $49.0(26.3)$ & $49.0(41.57)$ & $49.0(30.3)$ & n.s. \\
\hline & Constructional Praxis Recall, n (\%) & $46.9(23.8)$ & $37.5(43.3)$ & $44.7(28.2)$ & n.s. \\
\hline & CERAD Total Score ${ }^{\mathrm{a}}(0-111)$ & $62.8(9.8)$ & $44.8(8.8)$ & $58.8(12.1)$ & all: $\mathrm{p}=0.030(\mathrm{tau}), \mathrm{p}=0.046(\mathrm{p}-\mathrm{tau})$ \\
\hline & Word List Learning Efficiency ${ }^{\mathrm{b}}(1-10)$ & $1.5(0.5)$ & $1.6(0.7)$ & $1.5(0.5)$ & n.s. \\
\hline \multirow[t]{6}{*}{ MCI } & Verbal Fluency (0-24) & $13.7(3.4)$ & $15.3(5.1)$ & $14.7(4.5)$ & n.s. \\
\hline & Word List Delayed Recall & $2.6(1.9)$ & $4.5(1.8)$ & $3.8(2.0)$ & all: $p=0.017\left(A \beta_{1-42}\right)$ \\
\hline & Word List Delayed Recall, n (\%) & $45.6(29.2)$ & $68.6(27.2)$ & $60.1(29.4)$ & $\begin{array}{l}\text { men: } p=0.002\left(A \beta_{1-42}\right) \\
\text { all: } p=0.003\left(A \beta_{1-42}\right)\end{array}$ \\
\hline & Constructional Praxis Recall, n (\%) & $62.3(36.8)$ & $67.4(27.4)$ & $65.5(30.1)$ & n.s. \\
\hline & CERAD Total Score $^{\mathrm{a}}(0-111)$ & $58.4(13.6)$ & $71.6(15.5)$ & $67.2(15.7)$ & n.s. \\
\hline & Word List Learning Efficiency ${ }^{\mathrm{b}}(1-10)$ & $2.2(1.4)$ & $1.9(0.8)$ & $2.0(1.0)$ & $\begin{array}{l}\text { men: } p=0.018\left(A \beta_{1-42}\right) \\
\text { all: } p=0.036\left(A \beta_{1-42}\right)\end{array}$ \\
\hline \multirow[t]{6}{*}{ Control } & Verbal Fluency (0-24) & $17.3(4.8)$ & $19.0(1.7)$ & $18.1(3.8)$ & n.s. \\
\hline & Word List Delayed Recall & $5.4(2.5)$ & $6.0(1.3)$ & $5.7(2.1)$ & n.s. \\
\hline & Word List Delayed Recall, n (\%) & $77.2(30.1)$ & $97.6(5.8)$ & $85.4(25.3)$ & n.s. \\
\hline & Constructional Praxis Recall, n (\%) & $76.7(35.7)$ & $96.1(10.3)$ & $85.2(28.7)$ & all: $p=0.033\left(A \beta_{1-42}\right)$ \\
\hline & CERAD Total Score ${ }^{\mathrm{a}}(0-111)$ & $74.6(18.1)$ & $81.8(9.1)$ & $77.5(15.2)$ & n.s. \\
\hline & Word List Learning Efficiency ${ }^{\mathrm{b}}(1-10)$ & $1.6(0.3)$ & $1.8(0.6)$ & $1.7(0.5)$ & n.s. \\
\hline
\end{tabular}

Data are means (SD), unless otherwise indicated. The values marked in bold are the ones showing a significant correlation with one or more CSF biomarkers. The significant $\mathrm{p}$ values are given in the right column, separately for the different study groups.

Values missing from statistical analyses: Verbal Fluency: 1 AD woman, 1 frontotemporal dementia (FTD) man; Word List Delayed Recall: 1 control man; Constructional Praxis Recall: 5 AD women, 3 FTD women, 1 MCI woman, 1 other woman, 3 MCI men, 3 AD men, 3 other (depression, stroke/alcohol) men; CERAD Total Score: 4 AD women, 4 FTD women, 2 MCI women, 1 other woman, 3 AD men, 2 MCI men, 1 control man, 1 FTD man, 1 Parkinson's disease dementia man, 1 depression man, 1 other man; CSF tau: 1 MCI woman, 1 MCI man; CSF p-tau: 3 MCI women, 2 AD women, 1 control woman, 2 MCI men, 1 AD man, 1 depressed man; both CSF tau and CERAD Total Score: $1 \mathrm{MCI}$ woman; both CSF p-tau and Constructional Praxis Recall and CERAD total score: 1 AD man, 1 depressed man. n.s. = Not significant.

${ }^{\text {a }}$ According to Seo et al. [13]; ${ }^{\mathrm{b}}$ Word List Memory (3rd trial - 1st trial).

In the $\mathrm{AD}$ group including both men and women, the CSF tau concentration correlated significantly with the CERAD Total Score $(r=0.512, p=0.030)$, Memory Total Score $(r=0.501$, $\mathrm{p}=0.041)$ and the Executive Function score $(\mathrm{r}=0.446, \mathrm{p}=0.038)$, and CSF $\mathrm{p}$-tau concentration with the CERAD Total Score $(r=0.505, p=0.046)$ (table 2) and the Memory Total Score $(r=0.551, p=0.033)$. Interestingly, in this group women performed significantly better than men in Verbal Fluency (14.8 in women and 9.4 in men, $p=0.011$ ) and had a higher Executive Function score (21.0 in women and 12.9 in men, $p=0.019$ ) and CERAD Total Score (62.8 in women and 44.8 in men, $\mathrm{p}=0.012$ ) than men.

In controls, most subtests were significantly associated only with age and not the CSF biomarker concentrations, with the exception of Constructional Praxis Recall correlating with CSF p-tau ( $\mathrm{r}=-0.551, \mathrm{p}=0.033$ ) (table 2). 
Haapalinna et al.: Low Cerebrospinal Fluid Amyloid-Beta Concentration Is Associated with Poorer Delayed Memory Recall in Women

There was a statistically significant distinction between several CERAD-NB subtests in $\mathrm{AD}$ and MCI subjects. Moreover, the test performance of the AD group differed significantly from the control group: for instance, the Word List Delayed Recall performance was poorer $(\mathrm{p}=0.001)$ in the AD group compared to the controls (table 1$)$.

\section{Discussion}

In women in the total cohort, we found significant associations between the decrease in the CSF $A \beta_{1-42}$ concentration and CERAD-NB subtests and compound scores measuring delayed episodic memory. In men, none of the CSF biomarkers correlated with any subtests. The results in this study imply that women in this cohort may have more actual AD pathology reflecting the memory deficit than men, which would support the outcomes of previous studies showing a greater risk for $\mathrm{AD}$ in women $[25,26]$. Some previous studies have also shown that AD pathology may affect cognitive performance more in women than in men $[27,28]$, which may partly explain better correlation between CSF biomarkers and memory tests in women. Men, on the other hand, may have more other causes such as vascular comorbidity and Lewy Body Dementia behind the memory deficit $[29,30]$. The CSF biomarker concentrations were more pathologic in women than in men already at baseline (table 1). One may hypothesize whether this is simply due to the difference in the age distribution between the sexes, as the mean age in women was slightly higher than in men. The mean age in the cohort or within the diagnostic groups, however, showed no significant difference between men and women. In our cohort the correlation was clear, but due to some limitations of our study, the effect of age on results cannot be completely ruled out. De Deyn et al. [31], among others, have also shown that men would have a higher cognitive reserve at baseline than women, which could explain women's poorer memory performance. Our select cohort from a tertiary memory clinic may also have some effect on the results.

In our cohort, memory compound scores and the Executive Function score in CERAD-NB correlated significantly with CSF tau and p-tau concentration in the AD group, whereas in the MCI group, a similar relationship was found between $A \beta_{1-42}$ concentration and Word List Delayed Recall and Word List Learning Efficiency. This would support the hypothesis according to which the CSF $A \beta_{1-42}$ concentration changes already early in the course of the disease, while the increase in CSF tau and p-tau concentrations follows later when brain pathology is more pronounced and more severe memory deficits can be seen $[8,18]$. Our results are in agreement with some previous studies suggesting a stronger relationship between clinical memory problems and CSF tau than $A \beta_{1-42}$ concentration [15]. Moreover, in studies by Herukka et al. [32] and Zetterberg et al. [33], CSF tau and p-tau concentrations were found to be significantly increased and $A \beta_{1-42}$ concentration decreased in subjects with progressive MCI compared to controls and subjects with stable MCI, which also shows the association of these biomarkers with progressive cognitive decline. The significant negative correlation between CSF $A \beta_{1-42}$ and Word List Learning Efficiency $(r=-0.483, p=0.036)$ in $\mathrm{MCI}$ subjects, however, is not in agreement with other outcomes of this study and previous literature on the matter. A possible explanation for the aberrant results is the relative small sample size of our study, since especially in the subgroups the number of subjects was limited, making the statistical analyses less reliable. This may also explain the differences in memory performance between the sexes in the AD and MCI groups.

In our cohort, Word List Delayed Recall was found to correlate positively with CSF A $\beta_{1-42}$ concentration in women, but no such correlation was seen between its percentage value and CSF A $\beta_{1-42}$ concentration. This may be due to poor overall learning performance on the Word List Immediate Recalls. It has been proven that frontal regions of the brain also affect recall memory $[34,35]$. Therefore, if the amyloid pathology is focused in cortical areas in the frontal 
Haapalinna et al.: Low Cerebrospinal Fluid Amyloid-Beta Concentration Is Associated with Poorer Delayed Memory Recall in Women

regions of the brain, learning would become slower and memory retrieval ineffective already at the immediate recall.

The strengths of the study include a clinically relevant, poorly investigated subject, meticulous cognitive examination of the subjects with a validated neuropsychological test battery and quality controlled CSF measurements. Most previous studies on CSF biomarkers have been conducted in academic centers with highly standardized investigation methods, which may cause a bias, since many preanalytical factors may affect the biomarker levels. Thus, it is possible that these studies have overestimated the specificity of the markers in clinical practice of which our study may give a more realistic picture. However, the sample size could have been bigger. In addition, the lack of information about the subjects' APOE- $\varepsilon 4$ status and level of education was a limitation in our study, since these factors have been proven to remarkably affect the risk of $\mathrm{AD}$ and hence performance in cognitive tests [3]. Furthermore, our data included no depression screening of the subjects, although depression has been shown to have a significant effect on memory performance [36]. Moreover, our data included no information on vascular factors of the subjects, although they have been shown to be associated with cognitive decline [37]. Due to this, further studies are needed on the subject, including the factors previously mentioned, in addition to other diseases and risk factors, in order to gain a more comprehensive insight into the matter.

\section{Conclusions}

Results of our cohort imply that CSF biomarkers, particularly $\mathrm{A} \beta_{1-42}$, are associated with the delayed memory performance in CERAD-NB. Moreover, our results suggest that in this cohort women have more actual AD pathology at the time of the investigations than men, who may have other causes behind the memory deficit. In addition, patients with prodromal AD may be distinguished from patients with other memory deficits by evaluating their CSF A $\beta_{1-42}$ concentration and performance in memory tests measuring delayed episodic memory, as may the progression of MCI.

\section{Acknowledgements}

This study was funded by the EU project NADINE and The Academy of Finland (decision No. 263193) and is part of the BIOMARKAPD project in the frame of JPND. F.H. also received personal grants from The Finnish Brain Foundation, The Finnish Medical Foundation and The Finnish Medical Society Duodecim.

A large number of co-workers at the Department of Neurology also contributed to the collection of the data.

\section{References}

1 Mayeux R, Stern Y: Epidemiology of Alzheimer disease. Cold Spring Harb Perspect Med 2012;2:pii:aDD6239.

2 Querfurth HW, LaFerla FM: Alzheimer's disease. N Engl J Med 2010;362:329-344.

3 Ballard C, Gauthier S, Corbett A, Brayne C, Aarsland D, Jones E: Alzheimer's disease. Lancet 2011;377:1019_ 1031.

-4 McKhann GM, Knopman DS, Chertkow H, Hyman BT, Jack CR Jr, Kawas CH, Klunk WE, Koroshetz WJ, Manly JJ, Mayeux R, Mohs RC, Morris JC, Rossor MN, Scheltens P, Carrillo MC, Thies B, Weintraub S, Phelps CH: The diagnosis of dementia due to Alzheimer's disease: recommendations from the National Institute on Aging Alzheimer's Association workgroups on diagnostic guidelines for Alzheimer's disease. Alzheimers Dement 2011;7:263-269. 
5 Garcia-Alloza M, Subramanian M, Thyssen D, Borrelli LA, Fauq A, Das P, Golde TE, Hyman BT, Bacskai BJ: Existing plaques and neuritic abnormalities in APP:PS1 mice are not affected by administration of the gammasecretase inhibitor LY-411575. Mol Neurodegener 2009;4:19.

6 Price JL, Morris JC: Tangles and plaques in nondemented aging and 'preclinical' Alzheimer's disease. Ann Neurol 1999; 45:358-368.

7 de Leon MJ, Convit A, Wolf OT, Tarshish CY, DeSanti S, Rusinek H, Tsui W, Kandil E, Scherer AJ, Roche A, Imossi A, Thorn E, Bobinski M, Caraos C, Lesbre P, Schlyer D, Poirier J, Reisberg B, Fowler J: Prediction of cognitive decline in normal elderly subjects with 2-[(18)F]fluoro-2-deoxy-D-glucose/positron-emission tomography (FDG/PET). Proc Natl Acad Sci USA 2001;98:10966-10971.

8 Blennow K, Dubois B, Fagan AM, Lewczuk P, de Leon MJ, Hampel H: Clinical utility of cerebrospinal fluid biomarkers in the diagnosis of early Alzheimer's disease. Alzheimers Dement 2014;11:58-69.

-9 Tapiola T, Alafuzoff I, Herukka S, Parkkinen L, Hartikainen P, Soininen H, Pirttilä T: Cerebrospinal fluid $\beta$ amyloid 42 and tau proteins as biomarkers of Alzheimer-type pathologic changes in the brain. Arch Neurol 2009;66:382-389.

10 Blennow K, Hampel H, Weiner M, Zetterberg H: Cerebrospinal fluid and plasma biomarkers in Alzheimer disease. Nat Rev Neurol 2010;6:131-144.

11 Hansson 0, Zetterberg H, Buchhave P, Londos E, Blennow K, Minthon L: Association between CSF biomarkers and incipient Alzheimer's disease in patients with mild cognitive impairment: a follow-up study. Lancet Neurol 2006;5:228-234.

12 Paajanen T, Hanninen T, Tunnard C, Hallikainen M, Mecocci P, Sobow T, Tsolaki M, Vellas B, Lovestone S, Soininen H: CERAD neuropsychological compound scores are accurate in detecting prodromal Alzheimers disease: a prospective AddNeuroMed study. J Alzheimers Dis 2014;39:679-690.

13 Seo EH, Lee DY, Lee JH, Choo IH, Kim JW, Kim SG, Park SY, Shin JH, Do YJ, Yoon JC, Jhoo JH, Kim KW, Woo JI: Total scores of the CERAD neuropsychological assessment battery: validation for mild cognitive impairment and dementia patients with diverse etiologies. Am J Geriatr Psychiatry 2010;18:801-809.

14 Haldenwanger A, Eling P, Kastrup A, Hildebrandt H: Correlation between cognitive impairment and CSF biomarkers in amnesic MCI, non-amnesic MCI, and Alzheimer's disease. J Alzheimers Dis 2010;22:971-980.

15 Wagner M, Wolf S, Reischies FM, Wolfsgruber S, Jessen F, Popp J, Maier W, Hüll M, Frölich L, Hampel H, Perneczky R, Peters O, Jahn H, Luckhaus C, Gertz HJ, Schröder J, Pantel J, Lewczuk P, Kornhuber J, Wiltfang J: Biomarker validation of a cued recall memory deficit in prodromal Alzheimer disease. Neurology 2012;78: 379-386.

16 Rami L, Fortea J, Bosch B, Solé-Padullés C, Lladó A, Iranzo A, Sánchez-Valle R, Molinuevo JL: Cerebrospinal fluid biomarkers and memory present distinct associations along the continuum from healthy subjects to $\mathrm{AD}$ patients. J Alzheimers Dis 2011;23:319-326.

-17 Seppala TT, Koivisto AM, Hartikainen P, Helisalmi S, Soininen H, Herukka SK: Longitudinal changes of CSF biomarkers in Alzheimer's disease. J Alzheimers Dis 2011;25:583-594.

-18 Seppala TT, Nerg O, Koivisto AM, Rummukainen J, Puli L, Zetterberg H, Pyykkö OT, Helisalmi S, Alafuzoff I, Hiltunen M, Jääskeläinen JE, Rinne J, Soininen H, Leinonen V, Herukka SK: CSF biomarkers for Alzheimer disease correlate with cortical brain biopsy findings. Neurology 2012;78:1568-1575.

19 Buchhave P, Minthon L, Zetterberg H, Wallin AK, Blennow K, Hansson O: Cerebrospinal fluid levels of betaamyloid 1-42, but not of tau, are fully changed already 5 to 10 years before the onset of Alzheimer dementia. Arch Gen Psychiatry 2012;69:98-106.

-20 Dubois B, Feldman H, Jacova C, DeKosky S, Barberger-Gateau P, Cummings J, Delacourte A, Galasko D, Gauthier S, Jicha G: Research criteria for the diagnosis of Alzheimer's disease: revising the NINCDS-ADRDA criteria. Lancet Neurol 2007;6:734-746.

21 Petersen RC: Mild cognitive impairment as a diagnostic entity. J Intern Med 2004;256:183-194.

-22 Neary D, Snowden J.S, Gustafson L, Passant U, Stuss D, Black S, Freedman M, Kertesz A, Robert PH, Albert M, Boone K, Miller BL, Cummings J, Benson DF: Frontotemporal lobar degeneration: a consensus on clinical diagnostic criteria. Neurology 1998;51:1546-1554.

23 Chandler MJ, Lacritz LH, Hynan LS, Barnard HD, Allen G, Deschner M, Weiner MF, Cullum CM: A total score for the CERAD neuropsychological battery. Neurology 2005;65:102-106.

24 Hanninen T, Pulliainen V, Sotaniemi M, Hokkanen L, Salo J, Hietanen M, Pirttilä T, Pöyhönen M, Juva K, Remes A, Erkinjuntti T: Early detection of cognitive changes in memory diseases: new cut-off scores for the Finnish version of CERAD neuropsychological battery. Duodecim 2010;126:2013-2021.

25 Launer LJ, Andersen K, Dewey ME, Letenneur L, Ott A, Amaducci LA, Brayne C, Copeland JR, Dartigues JF, Kragh-Sorensen P, Lobo A, Martinez-Lage JM, Stijnen T, Hofman A: Rates and risk factors for dementia and Alzheimer's disease: results from EURODEM pooled analyses. EURODEM Incidence Research Group and Work Groups. European Studies of Dementia. Neurology 1999;52:78-84.

26 Andersen K, Launer LJ, Dewey ME, Letenneur L, Ott A, Copeland JR, Dartigues JF, Kragh-Sorensen P, Baldereschi M, Brayne C, Lobo A, Martinez-Lage JM, Stijnen T, Hofman A: Gender differences in the incidence of AD and vascular dementia: The EURODEM Studies. EURODEM Incidence Research Group. Neurology 1999;53:19921997.

27 Barnes L, Wilson R, Bienias J, Schneider J, Evans D, Bennett D: Sex differences in the clinical manifestations of Alzheimer disease pathology. Arch Gen Psychiatry 2005;62:685-691. 
28 Laws KR, Irvine K, Gale TM: Sex differences in cognitive impairment in Alzheimer's disease. World J Psychiatry 2016;6:54-65.

-29 Rosenberg C, Cummings T, Saunders A, Widico C, McIntyre L, Hulette C: Dementia with Lewy bodies and Alzheimer's disease. Acta Neuropathol 2001;102:621-626.

-30 Lerner A: Women and Alzheimer's disease. J Clin Endocrinol Metab 1999;84:1830-1834.

-31 De Deyn PP, Goeman J, Vervaet A, Dourcy-Belle-Rose B, Van Dam D, Geerts E: Prevalence and incidence of dementia among 75-80-year-old community-dwelling elderly in different districts of Antwerp, Belgium: the Antwerp Cognition (ANCOG) Study. Clin Neurol Neurosurg 2011;113:736-745.

-32 Herukka SK, Hallikainen M, Soininen H, Pirttila T: CSF Abeta42 and tau or phosphorylated tau and prediction of progressive mild cognitive impairment. Neurology 2005;64:1294-1297.

-33 Zetterberg H, Pedersen M, Lind K, Svensson M, Rolstad S, Eckerström C, Syversen S, Mattsson UB, Ysander C, Mattsson N, Nordlund A, Vanderstichele H, Vanmechelen E, Jonsson M, Edman A, Blennow K, Wallin A: Intraindividual stability of CSF biomarkers for Alzheimer's disease over two years. J Alzheimers Dis 2007;12:255260.

34 Stuss DT, Alexander MP: Executive functions and the frontal lobes: a conceptual view. Psychol Res 2000;63: 289-298.

-35 Becker S, Lim J: A computational model of prefrontal control in free recall: strategic memory use in the California Verbal Learning Task. J Cogn Neurosci 2003;15:821-832.

-36 Burt DB, Zembar MJ, Niederehe G: Depression and memory impairment: a meta-analysis of the association, its pattern, and specificity. Psychol Bull 1995;117:285-305.

-37 OBrien RJ: Vascular dementia: atherosclerosis, cognition and Alzheimer's disease. Curr Alzheimer Res 2011; 8:341-344. 